\title{
Effects of Bifidobacterium bifidum G9-1 on Nasal Symptoms in a Guinea Pig Model of Experimental Allergic Rhinitis
}

\author{
Satoru TsuneminE*, Yasuhiro ISA, Masaki SHIMAKAWA, Hiroshi OHNO and Hideki YAMAMURA \\ Biofermin Kobe Research Institute, Biofermin Pharmaceutical Co., Ltd., 7-3-4 Higashi-machi, Ibukidai, Nishi-ku, Kobe 651-2242, \\ Japan
}

Received August 12, 2010; Accepted October 29, 2010

Recent studies of several animal models have shown beneficial effects of probiotics against allergic responses. However, few reports have examined the effects of probiotics on allergic nasal symptoms such as sneezing and nasal obstruction in animal models of allergic rhinitis. This study evaluated the efficacy of Bifidobacterium bifidum G9-1 (BBG9-1) on antigen-induced nasal symptoms using guinea pig models of allergic rhinitis. Oral administration of BBG9-1 significantly inhibited antigen-induced allergic nasal reactions such as sneezing and nasal obstruction. Our results suggest that BBG9-1 may be useful for alleviating nasal symptoms in patients with allergic rhinitis.

Key words: probiotics; Bifidobacterium bifidum; allergic rhinitis; sneezing; nasal obstruction

\section{INTRODUCTION}

Allergic rhinitis has emerged as a major public health problem worldwide, and has become increasingly common in recent years (1). Allergic rhinitis is a typical allergic disease that shows various nasal symptoms such as sneezing, itching, nasal hypersecretion and nasal obstruction. Two types of allergic rhinitis are known: seasonal allergic rhinitis and perennial allergic rhinitis. Allergic rhinitis is associated with marked reductions in quality of life for patients, negatively affecting work productivity, school performance and social activities.

Probiotics are well known as viable bacteria with beneficial effects on human health (2-4). Many kinds of organisms have been used as probiotics, the most common being lactic acid bacteria, lactobacilli and bifidobacteria (5). Some probiotics have been used to improve symptoms resulting from changes in human intestinal flora $(6,7)$. Furthermore, several reports have revealed that these probiotics can help to protect against intestinal infection $(8,9)$, alter immunostimulation (10), and decrease elevated serum levels of cholesterol $(11,12)$ and glucose $(11,13,14)$ in several animal models.

Many recent reports have shown the beneficial effects of probiotics against allergic responses in several animal models (15-20). However, some reports have indicated strain-dependent differences in the ability of probiotics to modulate immune responses $(16,21,22)$. Furthermore, some reports have shown that oral treatment with probiotics suppresses serum total immunoglobulin $(\mathrm{Ig}) \mathrm{E}$

*Corresponding author. Mailing address: Biofermin Kobe Research Institute, Biofermin Pharmaceutical Co., Ltd., 7-3-4 Higashi-machi, Ibukidai, Nishi-ku, Kobe 651-2242, Japan. Phone: +81-78-993-4494. Fax:+81-78-992-6023. E-mail: tsunemine_satoru@biofermin.co.jp and/or antigen-specific IgE in several animal models, but few reports have examined whether oral treatment with probiotics suppresses allergic nasal symptoms such as sneezing, nasal itching and nasal obstruction in animal models of allergic rhinitis.

We previously reported that oral treatment with Bifidobacterium bifidum G9-1 (BBG9-1) suppresses serum total and antigen-specific IgE production in mice (23). BBG9-1 thus seems to be effective in the treatment of certain allergies. In the present study, to assess the potential value of the BBG9-1 probiotic strain as a therapeutic agent for allergic rhinitis, its effects on antigen-induced nasal symptoms were investigated using two different guinea pig models of allergic rhinitis: the sneeze model and the nasal obstruction model.

\section{MATERIALS AND METHODS}

\section{Preparation of bacterial cells}

BBG9-1 which was isolated from infant feces, was obtained from our laboratory. It was cultured at $37^{\circ} \mathrm{C}$ for $20 \mathrm{~h}$ in viande et foie broth (beef-liver extract) supplemented with $1 \%$ glucose and $0.04 \%$ cystine, then dried with sodium glutamate and dextrin. These preparations of BBG9-1 contained $2.2 \times 10^{11}$ colonyforming units (cfu)/g.

\section{Animals}

Male Hartley guinea pigs (4 weeks old) were purchased from Japan SLC (Hamamatsu, Japan). They were housed in an air-conditioned room at $22 \pm 3{ }^{\circ} \mathrm{C}$ and $55 \pm 5 \%$ humidity, with ad libitum access to standard laboratory diet (Labo G standard; Norsan, Yokohama, 


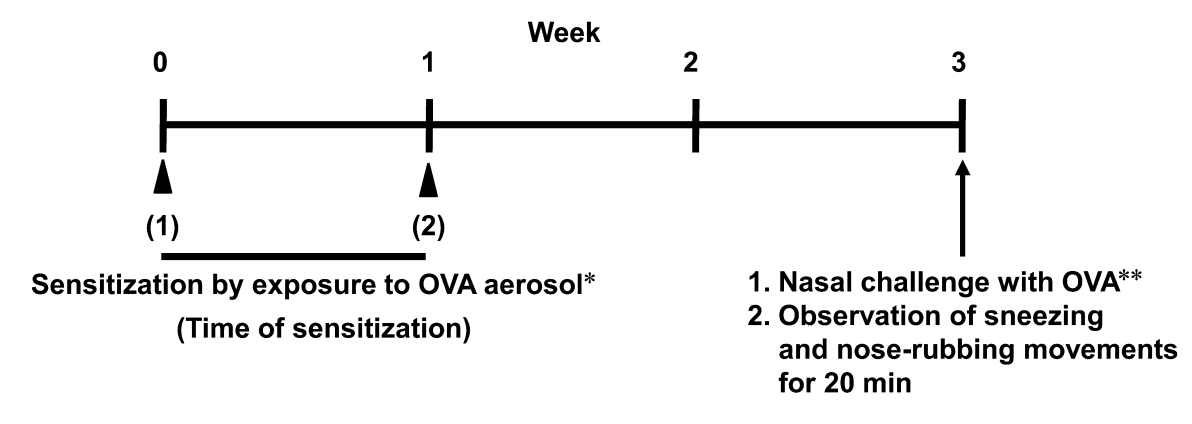

Oral administration of BBG9-1***

Fig. 1. Experimental design for the sensitization and challenge with OVA, and the oral administration of BBG9-1 in sneeze model.

* Exposed to $1 \%$ OVA aerosol for $10 \mathrm{~min}$; ${ }^{*} 0.4 \mathrm{mg}$ OVA$/ 20 \mu \mathrm{l}$ per nostril; *** $0.05 \mathrm{mg} / \mathrm{animal} / \mathrm{day}$.

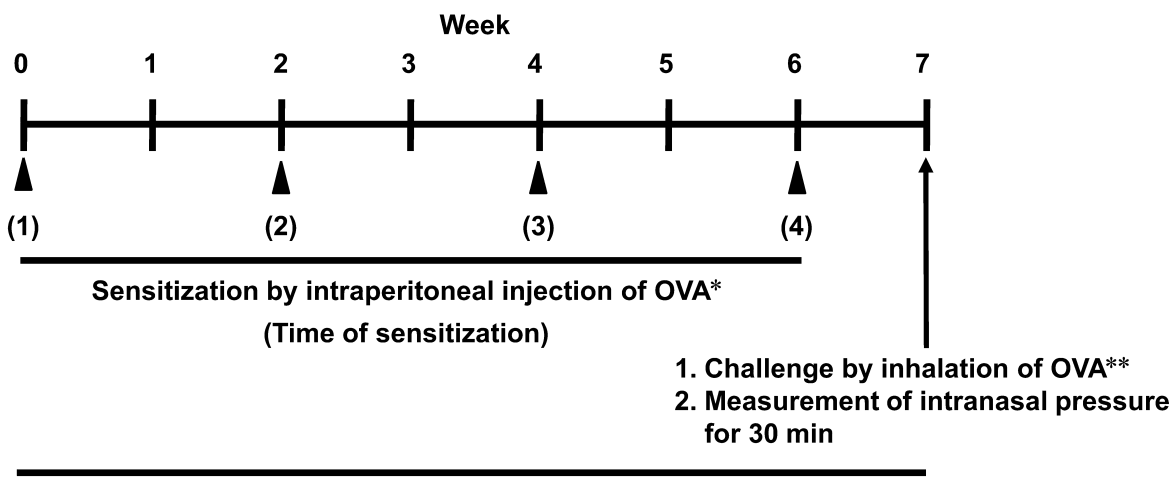

Oral administration of BBG9-1***

Fig. 2. Experimental design for the sensitization and challenge with OVA, and the oral administration of BBG9-1 in nasal obstruction model.

* $20 \mathrm{mg} \mathrm{OVA} / 5 \mathrm{mg} \mathrm{Al}(\mathrm{OH})_{3} / \mathrm{ml} / \mathrm{animal} /$ time; ** $3 \%$ OVA aerosol into nasal cavity for $3 \mathrm{~min}$; ** $0.05 \mathrm{mg} / \mathrm{animal} / \mathrm{day}$.

Japan) and water. All study protocols were approved by the Experimental Animal Care and Use Committee of Biofermin Pharmaceutical (Kobe, Japan).

\section{Measurement of antigen-induced sneezing and nasal itching}

The protocol followed in this study is shown in Fig. 1. Animals were randomly divided into three groups $(\mathrm{n}=10)$ and exposed to an ovalbumin (OVA; Sigma, St. Louis, MO) aerosol (1\%) for $10 \mathrm{~min}$ two times at a 1 -week interval. After the last antigen exposure, the animals were randomly allocated to cages, housed in groups of two per cage and acclimatized to the environmental conditions for $\geq 7$ days before the experiment. At 2 weeks after the last antigen exposure, nasal challenge was performed by topical application of OVA solution $(20 \mathrm{mg} / \mathrm{ml}, 20 \mu 1 \times 2)$ via nasal drops. Episodes of sneezing and nose-rubbing movements were counted for the first $20 \mathrm{~min}$ after antigen challenge. Nose-rubbing movements were assumed to represent an index of nasal itching.

BBG9-1 was suspended in saline and orally administered at a dose of $0.05\left(10^{7} \mathrm{cfu}\right) \mathrm{mg} / \mathrm{ml} /$ day $/$ animal using a polyvinyl chloride tube (ATOM indwelling feeding tube for infants, $5 \mathrm{Fr}$; Atom Medical, Tokyo, Japan) for 3 weeks after the first sensitization. As a control group, saline was orally administered at $1 \mathrm{ml} /$ day/animal for 3 weeks after the first sensitization. Furthermore, as a positive control group, ketotifen fumarate (Sigma, St. Louis, MO) was dissolved in saline and orally administered at $0.3 \mathrm{mg} / \mathrm{kg} / \mathrm{ml} /$ animal $1 \mathrm{~h}$ before nasal challenge.

\section{Measurement of antigen-induced intranasal pressure}

The protocol followed in this study is shown in Fig. 2. Animals ( 5 weeks old) were randomly divided into four groups $(n=10)$ and sensitized with an intraperitoneal injection of $20 \mu \mathrm{g}$ of OVA mixed with $5 \mathrm{mg}$ of $\mathrm{Al}(\mathrm{OH})_{3}$ in $1 \mathrm{ml}$ of saline four times at 2-week intervals. One week 
after the last sensitization, nasal reactions were measured according to the methods described by Fukuda et al. (24). Briefly, the animals were anesthetized with an intraperitoneal injection of $30 \mathrm{mg} / \mathrm{kg}$ of pentobarbital sodium. A cannula was inserted into the trachea, and the animals were allowed to breathe spontaneously through the cannula. A polyethylene cannula was inserted into the nasopharynx from the side of the larynx, and the other end of the cannula was connected to an artificial respirator set at a flow volume of $4 \mathrm{ml}$ and a frequency of 70 strokes/ min. The two duct pores, which are situated in the upper oral cavity wall and lead to the nasal cavity, were closed with Aron alpha $A^{\circledR}$ (Sankyo, Tokyo, Japan). Intranasal pressure was measured using a transducer (model DP4522; Validyne Engineering, Northridge, CA) connected to a lateral port at the proximal end of the endonasopharyngeal cannula. A saline or 3\% OVA aerosol, generated by an ultrasonic nebulizer (model 5000D; DeVilbiss Health Care, Somerset, PA) placed between the nasopharynx and the artificial respirator, was then insufflated into the nasal cavity for $3 \mathrm{~min}$. The increase in intranasal pressure was obtained by subtracting the pre-challenge baseline pressure. To evaluate the effects of BBG9-1, the area under the response curve (AUC) was calculated for the increase in intranasal pressure from 0 to $30 \mathrm{~min}$ after the end of ovalbumin inhalation.

BBG9-1 was suspended in saline and orally administered at a dose of $0.05\left(10^{7} \mathrm{cfu}\right) \mathrm{mg} / \mathrm{ml} /$ day $/$ animal using a polyvinyl chloride tube (ATOM indwelling feeding tube for infant, $5 \mathrm{Fr}$; Atom Medical, Tokyo, Japan), for 7 weeks after the first sensitization. As a control group, saline was orally administered at $1 \mathrm{ml} /$ day/animal for 7 weeks after the first sensitization. Furthermore, as a positive control group, ketotifen fumarate (Sigma, St. Louis, MO) was dissolved in saline and orally administered at $0.3 \mathrm{mg} / \mathrm{kg} / \mathrm{ml} /$ animal $1 \mathrm{~h}$ before nasal challenge.

\section{Statistical analyses}

Data are presented as mean \pm standard error of mean (SEM). Statistical evaluation of the results for sneezing and nose-rubbing was performed using the MannWhitney $U$ test. Statistical evaluation of the result for nasal obstruction was performed using Student's $t$-test or Welch's $t$-test after evaluation with the F-test when two groups were compared, or Dunnett's test when more than two groups were compared. Probability values of $P<0.05$ were considered statistically significant.

\section{RESULTS}

Influence on antigen-induced sneezing and nasal itching The application of OVA inside the nostrils induced sneezing and nose-rubbing in sensitized guinea pigs. Normal animals hardly responded to OVA solution. In the control group, sneezing and nose-rubbing movements were seen $13.2 \pm 1.8$ and $86.7 \pm 11.5$ times, respectively, when counted in the first $20 \mathrm{~min}$ after OVA challenge. BBG9-1 inhibited antigen-induced sneezing and noserubbing by $38 \%(P=0.0392)$ and $28 \%(P=0.2056)$, respectively (Fig. 3). No significant inhibition of sneezing and nose-rubbing occurred with a single administration of BBG9-1 by the same method as ketotifen (data not shown). However, administration of ketotifen $(0.3 \mathrm{mg} / \mathrm{kg})$ significantly inhibited both reactions.

\section{Influence on antigen-induced intranasal pressure}

In the control group, inhalation of OVA via the nasal cavity of anesthetized guinea pigs resulted in significantly increased intranasal pressure at $\geq 5$ min after OVA inhalation in comparison with the saline-challenge group (Fig. 4A). Increased intranasal pressure peaked at 30 min after OVA inhalation. Intranasal pressure in the BBG9-1 group increased more gradually over time after OVA inhalation than in the control group.

Figure $4 \mathrm{~B}$ shows the $\mathrm{AUC}_{0-30}$ min for intranasal pressure from 0 to $30 \mathrm{~min}$. $\mathrm{AUC}_{0-30 \mathrm{~min}}$ was significantly higher in the control group than in the saline-challenge group. $\mathrm{AUC}_{0-30 \text { min }}$ was significantly lower in the BBG91 group than in the control group $(P<0.05)$. On the other hand, administration of ketotifen $(0.3 \mathrm{mg} / \mathrm{kg})$ inhibited the reaction by $33 \%$, but the effect was not significant.

\section{DISCUSSION}

Allergic rhinitis is known to be associated with nasal symptoms such as sneezing, rhinorrhea, nasal obstruction, and itching. Sunada et al. (25) and Kawase et al. (26) recently reported that some Lactobacillus strains suppress such nasal symptoms in mouse and guinea pig models of allergic rhinitis. However, no reports have clarified whether bifidobacteria suppress nasal symptoms in experimental allergic rhinitis. We report here the first study to investigate the effects of bifidobacteria on nasal symptoms, sneezing and nasal obstruction, in an animal model of experimental allergic rhinitis.

We evaluated the efficacy of BBG9-1 in ameliorating sneezing and nasal obstruction using two different guinea pig models of experimental allergic rhinitis. BBG9-1 at an oral dose of $0.05 \mathrm{mg} /$ animal significantly inhibited 
(A) Sneezing

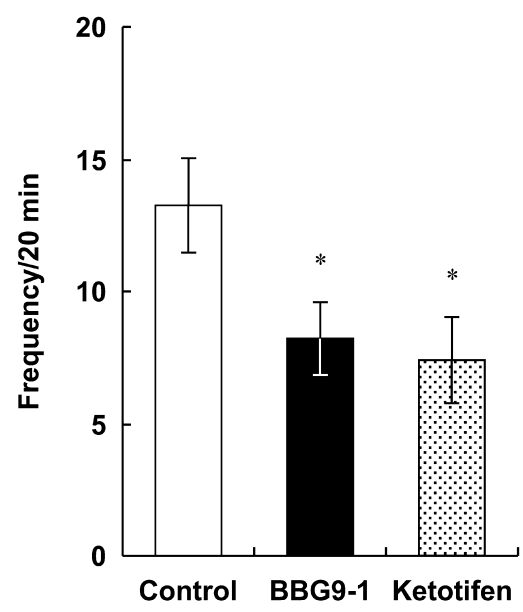

(B) Nose-rubbing

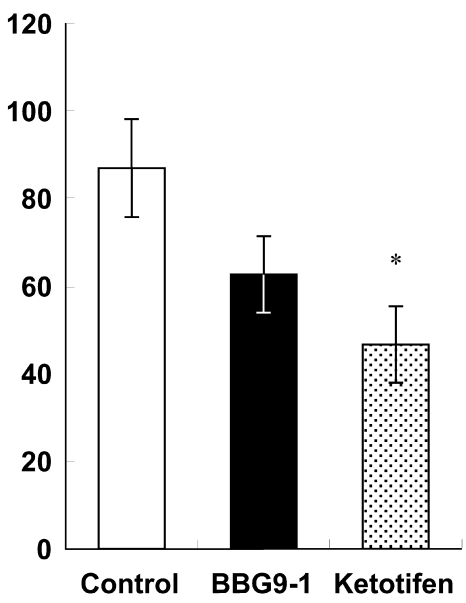

Fig. 3. Effect of BBG9-1 on occurrence of sneezing (A) and nose-rubbing (B) induced by antigen inhalation challenge with OVA in sensitized guinea pigs. Animals were sensitized by exposure to OVA aerosol (1\%) for $10 \mathrm{~min}$ two times at a 1 -week interval. Two weeks after the final sensitization, nasal challenge was performed by topical application of OVA solution $(20 \mathrm{mg} / \mathrm{ml}, 20 \mu 1 \times 2)$ via nasal drops. Sneezes and nose-rubbing movements were counted for the first 20 min after antigen challenge. BBG9-1 was administered orally for 3 consecutive weeks to animals after the first sensitization. Ketotifen fumarate was administered orally at $0.3 \mathrm{mg} / \mathrm{kg} / \mathrm{ml} /$ animal, $1 \mathrm{~h}$ before nasal challenge. Each column represents mean \pm SEM of 10 animals. $* P<0.05$ vs. control group.

antigen-induced nasal allergic responses such as sneezing and nasal obstruction in experimental allergic rhinitis (Figs. 3, 4). Inhibitory activity was found at quite a low dose compared with other reports $(25,26)$ of probiotic effects on experimental allergic rhinitis. These data suggest that BBG9-1 is useful for reducing antigeninduced nasal symptoms, and has high activity against allergic rhinitis compared with other probiotics.

Allergic responses are thought to be linked to Th2 lymphocytes that produce high levels of interleukin (IL)4, IL-5 and IL-6, which promote IgE synthesis (27). Probiotics have been shown to have the capacity to create conditions that facilitate a re-direction of allergeninduced Th2-skewed responses to a healthier, regulated Th1/Th2 balance $(16-18,28)$. We previously reported that BBG9-1 suppresses total and antigen-induced $\operatorname{IgE}$ production and Th2 cytokine production independent of Th1-inducing cytokine production (23). Furthermore, serum total IgE concentrations correlated directly with fecal Escherichia coli counts in allergic infants (29). Sudo et al. (30) reported that serum IgE levels in BALB/ c mice with intestinal flora disturbed by treatment with kanamycin were elevated compared to those in normal mice, and orally administered probiotics decreased these elevated IgE levels. We also reported that BBG9-1 is useful for the regulation of disturbed intestinal flora, particularly elevated $E$. coli in rats (31). The guinea pig models used in this study, the sneeze model and the nasal obstruction model, are thought to mainly involve antigenspecific $\operatorname{IgG}_{1}$ production $(32,33)$ and antigen-specific $\operatorname{IgE}$ production $(34,35)$, respectively. While consecutive oral administration of BBG9-1 significantly inhibited antigen-induced nasal allergic responses in both animal models, no effects were seen after a single administration of BBG9-1 before antigen challenge. Taking the results obtained by other researchers and our own findings together, BBG9-1 seems to directly or indirectly suppress antigen-specific antibody production by improving the Th1/Th 2 balance and/or the intestinal flora. Consequently, the development of allergic reactions due to affecting sensitization with antigen-specific antibody was prevented, regardless of the antibody class in these models.

Nasal allergic responses are mediated by the actions of released preformed and newly generated chemical mediators such as histamine, cysteinyl leukotrienes (CysLTs) and thromboxane (TX)A $\mathrm{A}_{2}$, which are released after activation of nasal mucosal mast cells and other inflammatory cells (36). Some investigations have indicated that histamine causes sneezing and nasalrubbing by binding to $\mathrm{H} 1$ receptors (H1Rs) at sensory nerve endings $(37-39,40)$, and some studies have found 


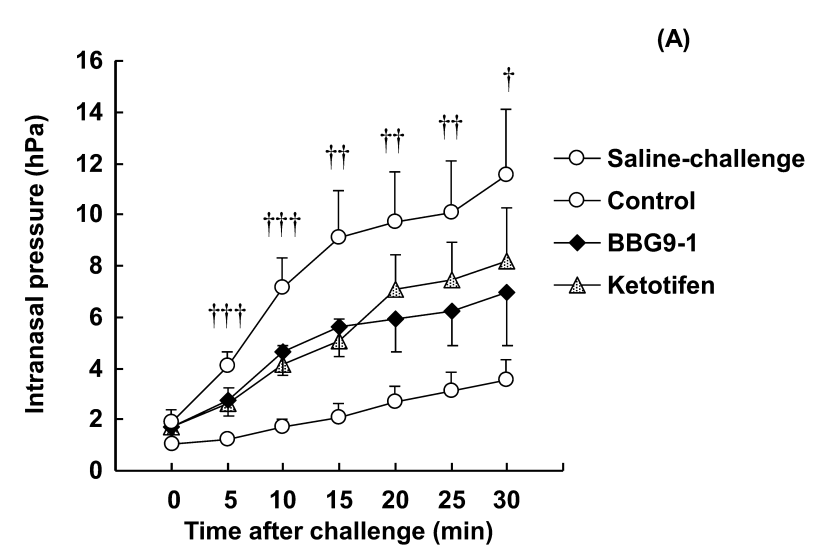

(B)

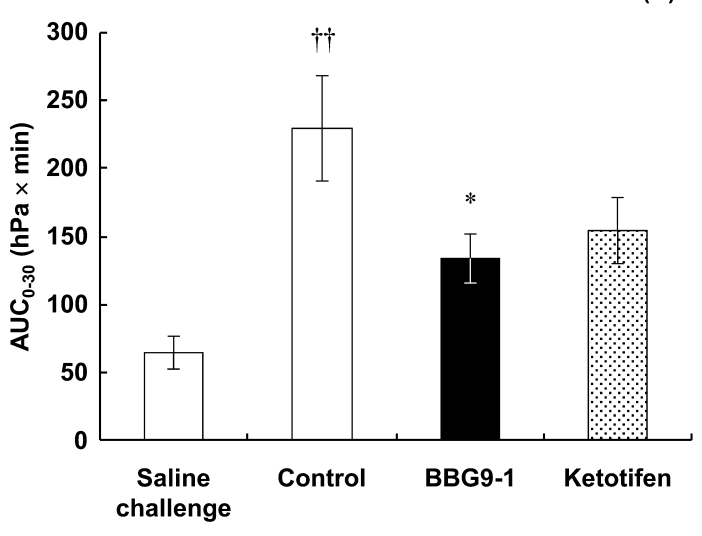

Fig. 4. Effects of BBG9-1 on time-course change (A) and area under the response curve (AUC) (B) of the increase in nasal pressure after antigen inhalation challenge with OVA in sensitized guinea pigs. Animals were sensitized by intraperitoneal injection of OVA $(20 \mu \mathrm{l})+\mathrm{Al}(\mathrm{OH})_{3}(5 \mathrm{mg})$ four times at 2 -week intervals. Sensitized animals were challenged by inhalation of OVA aerosol (3\%) for $3 \mathrm{~min}$. Intranasal pressure was measured for $30 \mathrm{~min}$ after cessation of inhalation. AUC was calculated for the increase in intranasal pressure from 0 to $30 \mathrm{~min}$ after the end of OVA inhalation. BBG9-1 was orally administered for 7 consecutive weeks to animals after the first sensitization. Ketotifen fumarate was orally administered at $0.3 \mathrm{mg} / \mathrm{kg} / \mathrm{ml} / \mathrm{animal}, 1 \mathrm{~h}$ before nasal challenge. Data represent mean \pm SEM of 10 animals. $\dagger P<0.05$ vs. saline-challenge group; $\dagger \dagger P<0.01$ vs. saline-challenge group; $\dagger \dagger \uparrow P<0.001$ vs. saline-challenge group; $* P<0.05$ vs. control group.

that H1R antagonists inhibit symptoms of allergic rhinitis in mouse and rat models $(41,42)$. In the present study, ketotifen, a H1R antagonist, inhibited nasal symptoms in our allergic rhinitis models after a single administration. However, BBG9-1 showed no significant inhibition of nasal symptoms after a single administration. The mechanisms by which allergic rhinitis is inhibited by BBG9-1 are thus clearly different from those of ketotifen.
In addition, Dev et al. (43) reported that consecutive oral administration of a mixture of Bifidobacterium infantis and Bifidobacterium longum showed significant antiallergic effects through inhibition of histamine signaling by suppressing both H1R and histidine decarboxylase (HDC) gene expression, followed by decreases in H1R and HDC protein levels, and histamine content in an animal model created by sensitization and provocation with toluene 2,4-diisocyanate. These observations lead us to suggest that part of the suppression mechanism of antigen-induced nasal symptoms by BBG9-1 may be associated with inhibition of histamine signaling. Further studies are needed to clarify the mechanisms by which BBG9-1 affects allergic rhinitis.

In conclusion, BBG9-1 showed significant inhibition of antigen-induced sneezing and nasal obstruction. These results suggest that BBG9-1 may be useful for treating nasal symptoms in patients with allergic rhinitis.

\section{ACKNOWLEDGMENTS}

The authors gratefully acknowledge the excellent technical assistance of Dr. T. Matsumoto from Takeda Chemical Industries. We also wish to thank Dr. Y. Ashida, Dr. S. Fukuda and Dr. M. Yamasaki of Takeda Chemical Industries for their expert technical advice.

\section{REFERENCES}

(1) Salib RJ, Drake-Lee A, Howarth PH. 2003. Allergic rhinitis: past, present and the future. Clin Otolaryngol Allied Sci 28: 291-303.

(2) Collins MD, Gibson GR. 1999. Probiotics, prebiotics, and synbiotics: approaches for modulating the microbial ecology of the gut. Am J Clin Nutr 69: 1052S-1057S.

(3) Drisko JA, Giles CK, Bischoff BJ. 2003. Probiotics in health maintenance and disease prevention. Altern Med Rev 8: 143-155.

(4) Salminen S, Bouley C, Boutron-Ruault MC, Cummings JH, Franck A, Gibson GR, Isolauri E, Moreau MC, Roberfroid M, Rowland I. 1998. Functional food science and gastrointestinal physiology and function. Br J Nutr 80(Suppl 1): S147S171.

(5) Furrie E. 2005. Probiotics and allergy. Proc Nutr Soc 64: 465-469.

(6) Fooks LJ, Gibson GR. 2002. Probiotics as modulators of the gut flora. Br J Nutr 88(Suppl 1): S39-S49.

(7) Young RJ, Huffman S. 2003. Probiotic use in children. J Pediatr Health Care 17: 277-283.

(8) Ogawa M, Shimizu K, Nomoto K, Takahashi M, Watanuki M, Tanaka R, Tanaka T, Hamabata T, Yamasaki S, Takeda Y. 2001. Protective effect of Lactobacillus casei strain Shirota on Shiga toxin- 
producing Escherichia coli $\mathrm{O} 157: \mathrm{H} 7$ infection in infant rabbits. Infect Immun 69: 1101-1108.

(9) Shu Q, Lin H, Rutherfurd KJ, Fenwick SG, Prasad J, Gopal PK, Gill HS. 2000. Dietary Bifidobacterium lactis (HN019) enhances resistance to oral Salmonella typhimurium infection in mice. Microbiol Immunol 44: 213-222.

(10) Perdigon G, Alvarez S, Rachid M, Aguero G, Gobbato N. 1995. Immune system stimulation by probiotics. J Dairy Sci 78: 1597-1606.

(11) Ohno H, Ishihara Y, Arai T, Yamamura H, Totani N, Ueda T. 2004. Effects of Bifidobacterium bifidum G91 on hypercholesterolemic and obese diabetic animal models. Bioscience Microflora 23: 109-117.

(12) Taranto MP, Medici M, Perdigon G, Ruiz Holgado AP, Valdez GF. 2000. Effect of Lactobacillus reuteri on the prevention of hypercholesterolemia in mice. J Dairy Sci 83: 401-403.

(13) Matsuzaki T, Nagata Y, Kado S, Uchida K, Kato I, Hashimoto S, Yokokura T. 1997. Prevention of onset in an insulin-dependent diabetes mellitus model, NOD mice, by oral feeding of Lactobacillus casei. APMIS 105: 643-649.

(14) Matsuzaki T, Yamazaki R, Hashimoto S, Yokokura T. 1997. Antidiabetic effects of an oral administration of Lactobacillus casei in a non-insulin-dependent diabetes mellitus (NIDDM) model using KK-Ay mice. Endocr J 44: 357-365.

(15) Forsythe P, Inman MD, Bienenstock J. 2007. Oral treatment with live Lactobacillus reuteri inhibits the allergic airway response in mice. Am J Respir Crit Care Med 175: 561-569.

(16) Fujiwara D, Inoue S, Wakabayashi H, Fujii T. 2004. The anti-allergic effects of lactic acid bacteria are strain dependent and mediated by effects on both Th1/ Th2 cytokine expression and balance. Int Arch Allergy Immunol 135: 205-215.

(17) Inoue Y, Iwabuchi N, Xiao JZ, Yaeshima T, Iwatsuki K. 2009. Suppressive effects of Bifidobacterium breve strain M-16V on T-helper type 2 immune responses in a murine model. Biol Pharm Bull 32: 760-763.

(18) Matsuzaki T, Yamazaki R, Hashimoto S, Yokokura T. 1998. The effect of oral feeding of Lactobacillus casei strain Shirota on immunoglobulin E production in mice. J Dairy Sci 81: 48-53.

(19) Torii A, Torii S, Fujiwara S, Tanaka H, Inagaki N, Nagai H. 2007. Lactobacillus acidophilus strain L-92 regulates the production of Th1 cytokine as well as Th2 cytokines. Allergol Int 56: 293-301.

(20) Yu J, Jang SO, Kim BJ, Song YH, Kwon JW, Kang MJ, Choi WA, Jung HD, Hong SJ. 2010. The effects of Lactobacillus rhamnosus on the prevention of asthma in a murine model. Allergy Asthma Immunol Res 2: 199-205.

(21) Ishida Y, Bandou I, Kanzato H, Yamamoto N. 2003.
Decrease in ovalbumin specific IgE of mice serum after oral uptake of lactic acid bacteria. Biosci Biotechnol Biochem 67: 951-957.

(22) Iwabuchi N, Takahashi N, Xiao JZ, Miyaji K, Iwatsuki K. 2007. In vitro Th1 cytokine-independent Th2 suppressive effects of bifidobacteria. Microbiol Immunol 51: 649-660.

(23) Ohno H, Tsunemine S, Isa Y, Shimakawa M, Yamamura H. 2005. Oral administration of Bifidobacterium bifidum G9-1 suppresses total and antigen specific immunoglobulin E production in mice. Biol Pharm Bull 28: 1462-1466.

(24) Fukuda S, Midoro K, Gyoten M, Kawano Y, Ashida Y, Nabe T, Kohno S, Nagaya H. 2003. Effects of TAK427 on acute nasal symptoms and nasal obstruction in guinea pig model of experimental allergic rhinitis. Eur J Pharmacol 476: 239-247.

(25) Sunada Y, Nakamura S, Kamei C. 2007. Effects of Lactobacillus acidophilus strain L-55 on experimental allergic rhinitis in BALB/c mice. Biol Pharm Bull 30: 2163-2166.

(26) Kawase M, He F, Kubota A, Harata G, Hiramatsu M. 2007. Orally administrated Lactobacillus gasseri TMC0356 and Lactobacillus GG alleviated nasal blockage of guinea pig with allergic rhinitis. Microbiol Immunol 51: 1109-1114.

(27) Foley S, Hamid Q. 2006. Inflammatory patterns in allergic rhinitis. Clin Exp Allergy Rev 6: 91-95.

(28) Shida K, Makino K, Morishita A, Takamizawa K, Hachimura S, Ametani A, Sato T, Kumagai Y, Habu S, Kaminogawa S. 1998. Lactobacillus casei inhibits antigen-induced $\operatorname{IgE}$ secretion through regulation of cytokine production in murine splenocyte cultures. Int Arch Allergy Immunol 115: 278-287.

(29) Kirjavainen PV, Arvola T, Salminen SJ, Isolauri E. 2002. Aberrant composition of gut microbiota of allergic infants: a target of bifidobacterial therapy at weaning? Gut 51: 51-55.

(30) Sudo N, Yu XN, Aiba Y, Oyama N, Sonoda J, Koga Y, Kubo C. 2002. An oral introduction of intestinal bacteria prevents the development of a long-term Th2skewed immunological memory induced by neonatal antibiotic treatment in mice. Clin Exp Allergy 32: 1112-1116.

(31) Isa Y, Ohgushi S, Yamashita M, Ishihara Y, Sakutani Y, Shimakawa M, Arai T, Ohno H. 2003. Effect of Bifidobacterium bifidum G9-1 on a constipation model induced by low-fiber diets in rats. Jpn J Med Pharm Sci 49: 745-751.

(32) Arimura A, Asanuma F, Matsumoto Y, Kurosawa A, Jyoyama H, Nagai H. 1994. Effect of the selective thromboxane $\mathrm{A}_{2}$ receptor antagonist, S-1452, on antigen-induced sustained bronchial hyperresponsiveness. Eur J Pharmacol 260: 201-209.

(33) Matsumoto T, Ashida Y, Tsukuda R. 1994. 
Pharmacological modulation of immediate and late airway response and leukocyte infiltration in the guinea pig. J Pharmacol Exp Ther 269: 1236-1244.

(34) Andersson P. 1980. Antigen-induced bronchial anaphylaxis in actively sensitized guinea-pigs. Pattern of response in relation to immunization regimen. Allergy 35: 65-71.

(35) Bahekar PC, Shah JH, Ayer UB, Mandhane SN, Thennati R. 2008. Validation of guinea pig model of allergic rhinitis by oral and topical drugs. Int Immunopharmacol 8: 1540-1551.

(36) Naclerio RM. 1991. Allergic rhinitis. N Engl J Med 325: $860-869$.

(37) Ohtsuka H, Okuda M. 1981. Important factors in the nasal manifestation of allergy. Arch Otorhinolaryngol 233: 227-235.

(38) Raphael GD, Meredith SD, Baraniuk JN, Druce HM, Banks SM, Kaliner MA. 1989. The pathophysiology of rhinitis. II. Assessment of the sources of protein in histamine-induced nasal secretions. Am Rev Respir Dis 139: 791-800.
(39) Shelton D, Eiser N. 1994. Histamine receptors in the human nose. Clin Otolaryngol Allied Sci 19: 45-49.

(40) Wang D, Smitz J, Waterschoot S, Clement P. 1997. An approach to the understanding of the nasal early-phase reaction induced by nasal allergen challenge. Allergy 52: $162-167$.

(41) Kayasuga R, Sugimoto Y, Watanabe T, Kamei C. 2002. Histamine $H 1$ receptors are involved in mouse nasal allergic responses: a demonstration with $\mathrm{H} 1$ receptor-deficient mice. Int Immunopharmacol 2: 745750.

(42) Sugimoto Y, Kawamoto E, Chen Z, Kamei C. 2000. A new model of allergic rhinitis in rats by topical sensitization and evaluation of $\mathrm{H}(1)$-receptor antagonists. Immunopharmacology 48: 1-7.

(43) Dev S, Mizuguchi H, Das AK, Matsushita C, Maeyama K, Umehara H, Ohtoshi T, Kojima J, Nishida K, Takahashi K, Fukui H. 2008. Suppression of histamine signaling by probiotic Lac-B: a possible mechanism of its anti-allergic effect. J Pharmacol Sci 107: 159-166. 